\title{
LOS PROCESOS DE GESTIÓN EDUCATIVA EN EL MARCO DE LA DESCENTRALIZACIÓN ${ }^{1}$
}

Piedad Caballero Prieto. ${ }^{2}$

\section{Introducción}

El estudio 'Transformaciones en los procesos de gestión educacional en el marco de la descentralización", realizado en cuatro países de la región: Argentina, Brasil, Chile y Colombia, planteó como objetivo "aportar modelos de gestión descentralizada en educación", a partir de experiencias e iniciativas exitosas para contribuir a su formulación.

Se entendió la descentralización como una opción de modernización y desarrollo autónomo, donde la comunidad local pasa a tener una participación preponderante en el manejo de lo financiero, administrativo y curricular, donde se involucra a la comunidad educativa y a la sociedad en general en la toma de decisiones y se promueven articulaciones con otros sectores de la sociedad como ONGs, sector empresarial y otros grupos organizados.

Determinar lo exitoso de la descentralización en nuestro caso, no fue tarea fácil. La Ley de Descentralización es muy reciente (1993), y en el momento de seleccionar la muestra ningún departamento había asumido plenamente las responsabilidades asignadas. Ninguno estaba certificado para asumir el manejo del situado fiscal que, en esencia, es lo que concretiza la descentralización.

¿Cómo, entonces, definir el éxito?, ¿en relación con qué?, ¿ligando el éxito de un establecimiento al de una política aún no implementada? ¿En relación con qué aspectos derivables de la descentralización se podría llegar a identificar proyectos exitosos? Interrogantes que se convirtieron posteriormente en directrices para el análisis.

Ante la complejidad del problema y luego de un amplio estudio exploratorio para seleccionar la muestra, se escogieron tres departamentos (Antioquia, Atlántico y Santander), dos pertenecientes al grupo seleccionado por el Ministerio de Educación Nacional y el Departamento Nacional de Planeación, para acompañar y asesorar el proceso de descentralización educativa, y otro, Santander. En cada departamento se seleccionaron cinco municipios que, en criterio de las autoridades departamentales y municipales, representan experiencias administrativas eficientes y "exitosas". En Antioquia: Bello, Rionegro, Gómez Plata, Carmen de Viboral y Copacabana. En el Atlántico: Baranoa, Sabanalarga, Soledad, Tubará y Santo Tomás. Bucaramanga, Piedecuesta, Floridablanca, Zapatoca y Tona en Santander.

Igualmente se seleccionaron dos establecimientos en cada municipio, reconocidos, en opinión de las autoridades y la comunidad, como de calidad y exitosos.

\footnotetext{
1 Síntesis del Proyecto "Transformaciones en los procesos de gestión educativa en el marco de la descentralización en Colombia", estudio realizado en el Instituto SER de Investigación por Piedad Caballero Prieto, Hortensia Manrique y un equipo de profesionales que apoyaron el trabajo de campo.

${ }^{2}$ Directora del Área de Educación del Instituto SER de Investigación. Codirectora PREAL - Col. 
Para obtener la información cualitativa se realizaron entrevistas estructuradas a diferentes actores. En el departamento a los secretarios de educación; en los municipios al Alcalde, al Secretario de Educación, al Director de Núcleo y a los Rectores.

En las instituciones escolares se aplicaron encuestas a docentes, a padres de familia y a alumnos, para tener un conocimiento sobre su organización, clima institucional y características consideradas determinantes del éxito.

Para el análisis cuantitativo, respecto de la institución, se utilizó información sobre estudiantes, docentes, repitencia, deserción, mortalidad, demanda y oferta, contenida en los formularios C-600 del DANE, con el propósito de estudiar desde una mirada evolutiva el efecto de estos indicadores en relación con la calidad y la cobertura. A nivel de municipio, se quiso analizar la evolución del manejo presupuestal, los aportes asignados para el sector, las fuentes de financiación, y la distribución del gasto e inversión. Y para lograr obtener una visión global de la educación en relación con otros sectores se elaboraron dos instrumentos que dieran cuenta de ello, pero esto no fue posible sino en muy pocos de los municipios estudiados. Además, la información que se obtuvo fue el resultado de un gran esfuerzo de reconstrucción por parte de los investigadores coordinadores del trabajo de campo en cada departamento.

Para el procesamiento y análisis de la información se elaboró una matriz de variables gruesas y se diseñó un software para su respectiva captura y consulta.

Como una actividad adicional, y como proceso de retroalimentación, se realizó un seminario-taller apoyado por el Ministerio de Educación Nacional, al cual asistieron los tres secretarios de educación de los departamentos seleccionados, algunos secretarios de educación municipal, directores de núcleo, rectores y docentes de algunos de los colegios estudiados, como también representantes del Ministerio de Educación, del Departamento Nacional de Planeación, de la Misión Social, FINDETER y el secretario de educación, que para esa época era el único certificado. El propósito fue corroborar, complementar y corregir la información, dado que en el momento en que ésta se recolectó, las nuevas administraciones estaban apenas incorporándose a sus nuevos cargos. Además, por el hecho de que los resultados encontrados eran muy positivos y animadores del proceso, consideramos necesario someter a discusión y apreciación, este hecho, frente al colectivo. Este espacio de reflexión y discusión permitió corroborar el análisis realizado, el cual se presenta a continuación.

\section{Reconstrucción del proceso de descentralización}

La descentralización aún no es una realidad en el país. Para analizar los cambios y transformaciones en la gestión educativa municipal e institucional objeto del estudio se partió, en nuestro caso, de la elaboración de un mapa legal ${ }^{3}$, que permitiera el estudio de la puesta en práctica de las normas a través de las cuales en los últimos años se ha venido cediendo funciones y responsabilidades a las entidades territoriales desde el nivel central, bien sean normas orientadas a la desconcentración o delegación de funciones, pero que en todo caso son acciones con las cuales se puede reconocer y reconstruir el proceso de descentralización.

Este proceso ha contribuido a generar ciertas prácticas, de orden local y en especial de las instituciones, las cuales indican avance y crecimiento, aunque éste no sea lo

\footnotetext{
${ }^{3}$ Realizado con el apoyo de Eduardo Aristizábal, investigador del Instituto SER de Investigación. 
suficientemente significativo ni tenga un impacto global, pero que no puede dejar de ser reconocido como positivo y alentador. Esta situación no permite establecer una relación directa entre las acciones de la escuela con las del municipio y demás instancias gubernativas, pues las dinámicas son diferentes. En el municipio, por ejemplo, el desarrollo responde más a la implementación de las políticas y normas, mientras que en la institución escolar obedece en mayor grado a procesos internos y autónomos.

Es claro que el proceso descentralizador ha tenido caminos diferentes y ha obedecido a necesidades e intereses diversos. En el municipio ha contribuido a una planeación más participativa, involucrando a distintos actores de la administración y de la comunidad. En cuanto a la institución escolar se ha promovido la participación de la comunidad en la vida escolar, se han creado espacios para la cooperación y apoyo entre las instituciones escolares y sociales, lo cual constituye una búsqueda de democratización de la escuela. Hay que resaltar que la generación de procesos activos y significativos de participación de la comunidad en el proceso educativo, impulsados desde las instituciones, bien sea para mejorar los procesos organizacionales, administrativos y pedagógicos o para buscar mejorar la calidad y pertinencia de la educación, dependen más, como ya se mencionó, del interés del colectivo de la institución que de influencias externas, aunque en la actualidad éstas sean coherentes con las políticas y normas actuales.

Existen avances importantes en la educación colombiana y en el proceso de descentralización, los cuales son más evidentes respecto del municipio y de las instituciones educativas. Circunstancia o evidencia que pudo ser constatada desde un punto de vista cualitativo y no cuantitativa, pues a nivel de la información estadística se presenta una gran debilidad, por no decir que hay carencia de información. Luego, haber abordado el problema desde esta perspectiva cualitativa es un logro, dado que posibilita animar el proceso y apoyar su desarrollo, lo cual no es posible desde un plano meramente cuantitativo.

Del análisis de la información obtenida se puede afirmar lo siguiente:

1. El hecho de asumir la descentralización es una circunstancia que obliga a cambiar profundamente las prácticas tradicionales y el modo como se asumen los problemas y se toman las decisiones.

2. Hay conciencia, en general, sobre las ventajas que ofrece la descentralización en cuanto a mayor y mejor conocimiento de la realidad local, mayor y mejor planeación y, por ende, una mejor y más adecuada administración del recurso humano y financiero. Entre alcaldes, secretarios de educación departamental y municipal, directores de núcleo, rectores de establecimientos educativos, al igual que en la comunidad educativa, representada en los docentes, alumnos y padres de familia, hay conciencia de la necesidad de impulsar, por sí mismos, los procesos en los que están involucrados, y satisfacción de poder participar directamente en la construcción de su inmediato futuro.

3. En relación con el proceso global de descentralización existe la evidencia de que uno es el proceso que se da cuando la descentralización es decidida desde el centro, y otro el que resulta cuando es producto de un esfuerzo requerido y una práctica espontánea de la comunidad interesada. 
4. Exceso de normatividad que genera contradicciones e incoherencias en lo que impide el avance, desarrollo y compromiso de la sociedad y de las autoridades en proyectos y procesos como este.

5. La comunicación y coordinación entre los distintos niveles es reconocida en general como buena, pero en la práctica no lo es; existen problemas, lo que dificulta el proceso. La información no fluye y es diferente entre las distintas instancias.

6. El grado de conocimiento del proceso de descentralización a través de las normas, mecanismos de coordinación y respuestas a solicitudes del nivel central por parte de los funcionarios de los diferentes niveles permite afirmar que existe información sobre el tema y un conocimiento sobre el compromiso del funcionario frente al proceso. Sin embargo, no sucede lo mismo entre otros actores consultados, como docentes, alumnos y padres de familia.

7. La información cualitativa obtenida es muy rica y permite la realización de análisis importantes frente a posibilidades, ventajas, desventajas y limitaciones del modelo y del proceso; pero la información cuantitativa, tanto respecto del departamento como del municipio y del establecimiento, no sólo es pobre y deficiente, sino que se percibe una indiferencia frente a ella. Tal parece que carece de sentido y utilidad, no existe un aprovechamiento de ésta, y hay una carencia total de una cultura de la información.

\section{La descentralización en la educación}

La descentralización educativa está enmarcada en el proceso general de descentralización administrativa, política y fiscal que ha vívido el país, la cual ha sido manifestada en diferentes normas ${ }^{4}$, expedidas desde 1983 hasta el presente, a través de las cuales se ha ido evolucionando desde la transferencia de funciones administrativas a los municipios y el fortalecimiento de la democracia local, hasta la asignación de competencias y responsabilidades en la dirección, administración, financiación y manejo de los recursos del situado fiscal y de las trasferencias de recursos de la nación a los municipios.

En educación, la descentralización se inició con la desconcentración de funciones desde el nivel central al departamento y posteriormente al municipio, proceso que se inició con la creación de los Fondos Educativos Regionales (FER), para agilizar el pago de maestros, los Centros Experimentales Piloto (CEP), responsables de la capacitación de los docentes y dependientes del Ministerio de Educación, y las juntas seccionales de escalafón, para atender en el orden seccional los problemas del personal docente.

El decreto-ley 077 de 1987 traspasó funciones a los municipios en materia de construcción, dotación y mantenimiento de planteles e instalaciones. En 1988 se crean las

\footnotetext{
${ }^{4}$ La Ley 12 de 1986 incrementó la transferencia del IVA a los municipios, del 30 al 50\%. La Ley 14 de 1986 incrementó al impuesto predial y el de industria y comercio en los municipios. El Acto Legislativo No. 1 estableció la elección popular de alcaldes. La Ley 1333 establece el Código de Régimen Municipal. La Ley 11 crea las juntas administradoras locales. En 1987 se establece el Estatuto de Descentralización. En 1989 se efectúa la consulta popular (Ley 42) y se reglamentan los planes de desarrollo municipal (Ley 9a4. En 1991 es creado el Programa de Desarrollo Institucional y se promulga la nueva Constitución. En 1992, la Ley 2132 determina los mecanismos de cofinanciación. En 1993, la Ley 60 aborda de manera integral la descentralización y distribución de competencias y recursos. En 1994, la Ley 152 legisla sobre los planes de desarrollo y Concejos.
} 
juntas educativas, y con la ley 29 de 1989 se promueve la municipalización de la educación.

En 1990 se reglamenta el sistema de nuclearización mediante el decreto 1246 con el fin de mejorar la administración, organizar y adecuar el servicio educativo a las necesidades comunitarias, apoyando así el desarrollo de la educación en el ámbito local.

A partir de la Constitución de 1991 se establece la educación como un derecho fundamental, como un servicio público con función social y como instrumento para contribuir a la creación del nuevo modelo de país, de la democracia participativa, la justicia social y el desarrollo integral. Estos aspectos fueron retomados plenamente en la Ley General de Educación (Ley 115 de 1994) a través de la reestructuración y organización del sistema educativo; de los componentes, estrategias y mecanismos ideados para promover el cambio y ajuste a las circunstancias actuales nacionales, regionales e internacionales.

Los proyectos educativos institucionales, establecidos como obligatorios a partir de la ley 115, serán elaborados por la comunidad educativa. En ellos se busca mejorar la calidad de la educación, la participación de la comunidad y crear mejores condiciones para la atención de poblaciones especiales o minoritarias. Además, otorgan autonomía a los establecimientos educativos, tocante al currículo, se busca una adecuación a las necesidades regionales teniendo en cuenta la cultura, y la relación con conocimiento y avance de la ciencia y la tecnología. Promueve, además, la evaluación participativa en el plano institucional.

La ley 115 establece disposiciones para la administración educativa en los municipios y redefine el núcleo como la unidad operativa local de la planeación y administración. Reafirma las juntas municipales de educación y establece la realización de foros educativos anuales en el municipio. Promueve la inversión en educación, a través del sistema de cofinanciación, de créditos blandos para la construcción y remodelación de establecimientos educativos y promueve estímulos para los municipios, instituciones, maestros y alumnos.

El proceso de descentralización está apoyado, a nivel nacional, por el Ministerio de Educación y por la Misión Social, creada para este fin, quienes proporcionan asesoría, acompañamiento y realizan talleres para el análisis critico sobre aspectos del proceso.

Normativamente podría decirse que existe un modelo de descentralización, conformado por los elementos que aparecen en las gráficas Números 1,2 y3.

\section{De la norma a la realidad}

Fueron analizados los componentes fiscales, administrativos y pedagógicos acordados para el estudio. Sin embargo, es importante señalar que en lo político también han sucedido hechos importantes durante el proceso descentralizador, tales como la elección popular de alcaldes, de gobernadores y de representantes a las juntas administradoras locales (JAL), situación que ha significado el diseño de políticas y programas para estos niveles, lo cual implica control social, pues la comunidad reclama el cumplimiento de los proyectos y programas ofrecidos por los candidatos.

Podría afirmarse que en el proceso de descentralización han existido dos momentos: el de la formulación teórica y el de la puesta en escena. En Colombia se ha avanzado 
ampliamente en el primer aspecto, y el segundo se encuentra en su fase inicial de organización, ajuste y diseño de estrategias y metodologías para su desarrollo.

\section{Gráfico No. 1 COMPETENCIAS}
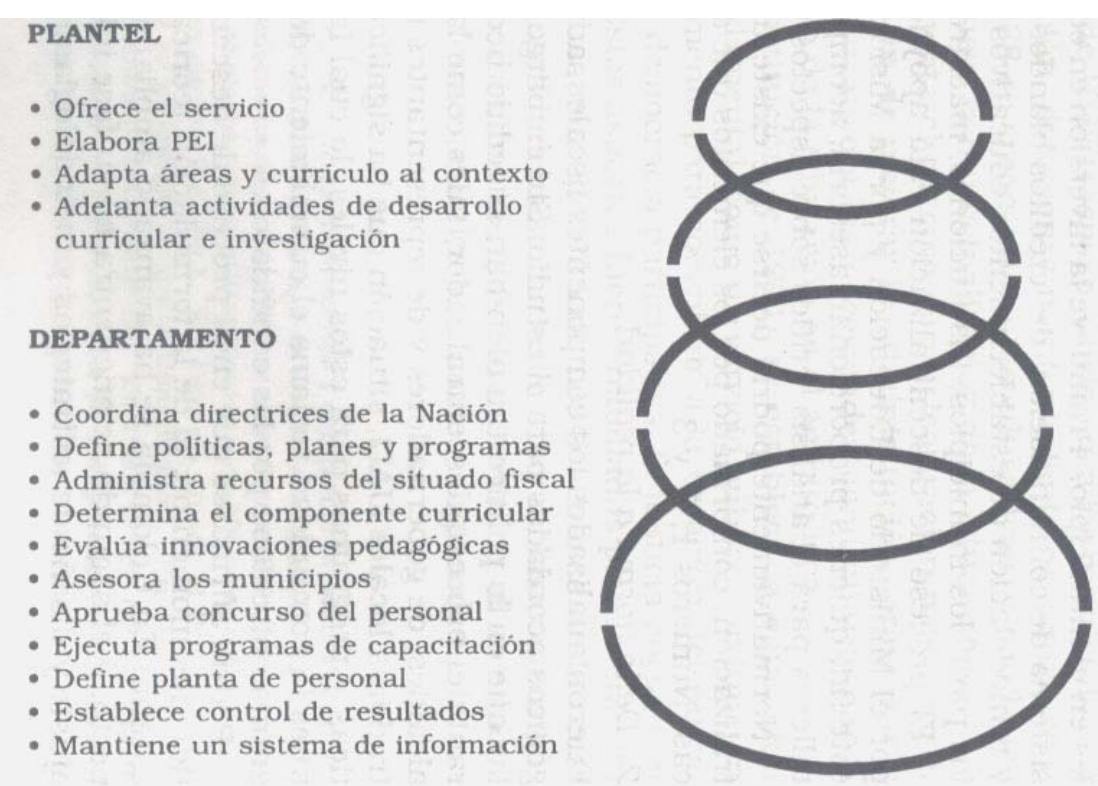

MUNICIPIO

- Administra personal

- Administra recursos financieros

- Administra planta fisica

- Establece estructuras especificas

- Aplica currículos o innovaciones

- Ejerce inspección y vigilancia

NACIÓN

- Orienta sobre directrices y marcos juridicos

- Establece estructuras marco para el manejo de recursos

- Plantea lineamientos curriculares

- Promueve innovaciones pedagógicas

- Diseña esquemas para: concurso de personal capacitado, evaluación, sistema de información

Vale la pena resaltar que la descentralización, más que un marco normativo es un proceso cultural, social, político y económico, y que para pensar en resultados se debe desarrollar y estudiar dicho proceso de manera integral, esfuerzo que se ha tratado de realizar en este estudio. Esto implica que, además del seguimiento a la implementación de la norma, se deben promover y estimular procesos de orden cultural que contribuyan a modificar las actitudes para superar la renuencia al cambio, la indiferencia a participar activamente en la toma de decisiones y superar la burocratización de la administración.

Es necesario aceptar las nuevas reglas de juego, las cuales modifican las relaciones de poder, requieren una mayor capacidad técnica y de gestión por parte de las entidades territoriales y del nivel central, al igual que la precisión de normas para superar las contradicciones jurídicas.

Desde esta perspectiva, hay que reconocer que la política más avanzada en este proceso es la relacionada con la nuclearización. En la mayoría de los municipios, operan núcleos de desarrollo educativo que de una manera u otra han contribuido al desarrollo local. La ley 29 de 1989, parte del proceso, no fue implementada en todos los municipios del país, pese a ser reconocida como importante en la línea que apunta al desarrollo local. La ley 60 de 1993, que es la que concretiza y concluye el proceso normativo, no ha sido puesta en práctica. Sólo tres departamentos, y muy recientemente, han obtenido la respectiva certificación para manejar autónomamente los recursos del situado fiscal ${ }^{5}$.

La ley 115 en su implementación ha marchado más ágilmente que la ley 60 y se notan mayores avances y movimientos respecto de las instituciones, ya que éstas son más

\footnotetext{
${ }^{5}$ Esta etapa de la investigación se concluyó en diciembre de 1995. Es importante aclarar que para la fecha en que aparece esta publicación ya se han certificado más de doce departamentos.
} 
ágiles y dinámicas que los municipios y departamentos. Además porque la ley 115 retomó prácticas ya existentes y legitimó aspectos de la educación que ya estaban en marcha.

La percepción que existe sobre la descentralización por parte de los actores entrevistados es que ésta representa mayores ventajas que desaciertos.

Las ventajas se manifiestan:

1) En lo financiero, por la disponibilidad de mayores recursos para el sector educativo, la utilización de los mecanismos de cofinanciación, la posibilidad de realizar convenios y la obligatoriedad de utilizar mayor porcentaje de los recursos transferidos para la inversión.

2) En lo administrativo, por el mejoramiento en la gestión, el incremento de mecanismos de control - muchos de ellos ciudadanos-, la disminución en la tramitología, y la agilización en la contratación de docentes según las necesidades locales. Se percibe además un acercamiento entre el Estado y la comunidad, con lo que se desarrolla una mayor conciencia y autonomía local y capacidad para decidir acertadamente sobre los problemas.

3) En lo pedagógico, el desarrollo de la autonomía institucional, la democratización de la institución, la construcción colectiva del Proyecto Educativo Institucional, lo cual vincula e integra a la comunidad, la elección del Gobierno Escolar, del Personero Estudiantil y la organización de las diferentes asociaciones.

Entre las desventajas se señalan:

a) En lo fiscal y financiero: insuficiencia de recursos para atender las responsabilidades; el hecho de que municipios con menos de 100.000 habitantes no puedan gestionar el situado fiscal, y la imposibilidad de utilizar recursos de transferencia para funcionamiento.

b) En lo administrativo: falta de precisión en materia de competencias entre los entes territoriales; existencia de regímenes diferentes para la administración de personal y el hecho de que aún persistan criterios clientelistas en los nombramientos, y la falta de asesoría frente a la débil capacidad de gestión en los municipios.

c) En lo pedagógico: falta de autonomía para los traslados, nombramientos y para el manejo de recursos; la no asignación de recursos a los fondos educativos, la falta de capacitación y asesoría para la implementación de la ley.

\section{La descentralización en la práctica}

\subsection{La descentralización administrativa}

Teniendo en cuenta la responsabilidad y operación en todo el proceso de descentralización, se analizaron aspectos relacionados con: la administración de los establecimientos, la organización para la prestación del servicio, planeación, participación, prácticas evaluativas, supervisión, capacitación y la coordinación entre los diferentes estamentos. Del análisis realizado se llegó a las siguientes apreciaciones:

Administración de los establecimientos. Esta recae en los municipios los cuales manifiestan tener problemas de orden económico, jurídico, administrativo y político. Sólo 
en dos de los quince municipios estudiados las autoridades manifestaron no tener dificultades. En materia económica existe insuficiencia de recursos para el nombramiento de docentes, para efectuar el mantenimiento y dotación de los establecimientos y para cumplir con las nuevas responsabilidades asignadas. En lo jurídico se destaca el desconocimiento de las normas vigentes, así como la carencia de retroalimentación para el ajuste de algunos aspectos relacionados con decisiones que afectan el cumplimiento de otras normas. La no aplicación por parte de algunos nominadores y concejos municipales de las normas relativas a salarios y prestaciones, la existencia de establecimientos sin legalizar, que imposibilita la inversión por parte del gobierno para su mejoramiento, la falta de autonomía de las secretarías de educación para nombrar los docentes, circunstancia que en ocasiones conduce a un manejo clientelista de la planta docente. Finalmente, se presenta un excesivo uso de la tutela ${ }^{6}$ para exigir traslados.

En lo administrativo, se adolece de falta de precisión en las responsabilidades asignadas al alcalde, al secretario de educación municipal y al director de núcleo. Existe deficiencia en la actualización del personal administrativo y se presentan amenazas a los docentes por problemas de orden público, lo cual es una consecuencia directa de la falta de autonomía para resolver estos problemas. En lo político destacan las prácticas clientelistas para el nombramiento, traslado y solución de problemas laborales de los maestros. Se evidencia el hecho de que para la clase política local, en algunos municipios, la educación no es una preocupación, y menos una prioridad.

Organización para la prestación del servicio. El gráfico No. 2 muestra la estructura organizativa, la cual internamente puede variar. Santander y Antioquia, por ejemplo, se encuentran en reestructuración para incorporar el Fondo Educativo Regional (FER), el Centro Experimental Piloto (CEP) y la Oficina de Escalafón, estamentos que dependían anteriormente del Ministerio de Educación Nacional (MEN).

En algunos municipios pequeños las funciones educativas las ejerce el alcalde con la colaboración del director de núcleo. De los municipios estudiados, nueve cuentan con Secretaría y en los otros seis, los directores de núcleo cumplen esta función.

\footnotetext{
${ }^{6}$ La tutela es una figura jurídica establecida por la Constitución de 1991, la cual permite a los ciudadanos demandar ante un juez la violación de algún derecho individual y fundamental establecido por la Carta Magna. Los docentes instauran tutelas cuando la administración decide trasladarlos a un sitio en el cual ellos no están interesados. La tendencia general de los docentes es ejercer su labor en las áreas urbanas.
} 


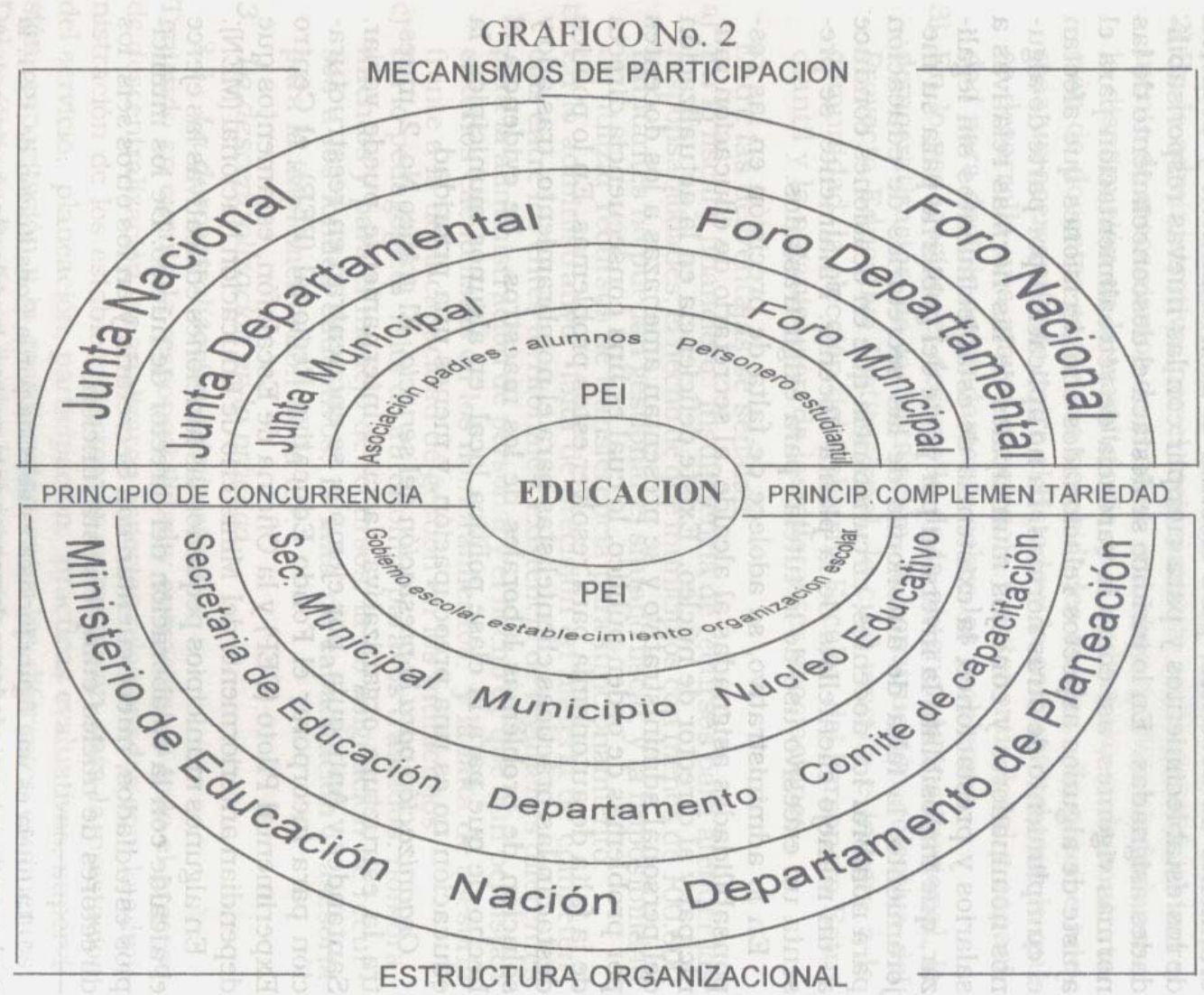

Todos los municipios estudiados cuentan con núcleos de desarrollo educativo conformados por un director de núcleo y un consejo organizado por comités operativos. La norma establece para los núcleos funciones administrativas, de planeación, programación de actividades, elaboración de diagnósticos, asesoría, coordinación, información estadística, capacitación y pedagogía. Sin embargo, su labor se centra en lo administrativo, dejando en un segundo plano la asesoría a los planteles, por cuanto éstos se dedican a apoyar la gestión del Alcalde, la del Secretario de Educación y a brindar atención a los padres de familia.

Esta instancia es considerada por los diferentes actores consultados como eje de la descentralización, ya que facilita la solución de problemas locales, genera acercamiento entre los docentes y el municipio, permite la unificación de políticas y criterios de trabajo en los establecimientos educativos, a la vez que es un canal de coordinación y comunicación entre los establecimientos, la comunidad y las autoridades municipales. Presenta algunos vacíos relacionados con la actividad de planificación local一, pese a que participan en la formulación del plan de desarrollo educativo,_- debilidad en la asesoría técnico-pedagógica a los establecimientos; y en la organización y operación, consecuencia de la falta de personal de apoyo secretarial, pedagógico, psicológico y de trabajo social, de recursos materiales, y en el hecho de tener bajo su responsabilidad un número de establecimientos mayor al contemplado en la norma.

Los núcleos gozan de un gran reconocimiento en todos los estamentos, excepto en el de los docentes de aquellos establecimientos que están bajo su jurisdicción. 
Planeación y participación. Se observa un cambio en la dinámica de planeación. Hay una mayor participación de la comunidad en la elaboración de los planes de desarrollo educativo, los cuales se basan en diagnósticos que buscan dar respuesta y solución a los problemas, por iniciativa de la comunidad. Casi todos los municipios reportaron haber formulado planes de desarrollo para el sector educativo. Esto puede significar que con el proceso de descentralización se ha iniciado el desarrollo de la autonomía local, se ha incentivado la creatividad y la iniciativa de los municipios y se está superando el modelo de planeación rígido, orientado por instancias que impedían dar cuenta de las necesidades locales. La planeación se ha acercado a la problemática local pese a las dificultades para su implementación, dado el exceso de trabas en los organismos que definen la asignación de los recursos.

En los núcleos, según sus directores, se organizan actividades a través de los planes y se establecen cronogramas de trabajo elaborados por diferentes comités. En los establecimientos educativos, según los rectores, se realizan labores de planeación, diseño de políticas internas y planeación de los aspectos pedagógicos, con participación de la comunidad, en algunos casos.

Los establecimientos educativos han desarrollado su Proyecto Educativo Institucional (PEI) en aras de la autonomía. Se ha iniciado la democratización de la institución con la participación de la comunidad en la toma de decisiones para la definición de políticas internas y las metas de sus respectivos proyectos.

Se podría decir que a nivel local se está construyendo una nueva cultura de la planeación y de la participación. Sin embargo, el proceso es afectado por la carencia de información, pues existen algunos formatos para su recolección, los cuales son diligenciados de manera poco técnica, por lo cual presentan vacíos e inconsistencias que impiden un análisis confiable.

Frente a la carencia de información confiable, indispensable para el éxito de la descentralización y la gestión, la Misión Social ha elaborado un software denominado SABE-50, para obtener información básica sobre planteles educativos, docentes y alumnos, sistema que está siendo utilizado en algunos departamentos, entre ellos los tres estudiados en el marco de la investigación.

La precariedad de la información quedó evidenciada, pues fue imposible disponer de ella para realizar el análisis de carácter presupuestal, de inversión en educación y distribución del gasto, así como para poder abordar desde esta variable la preocupación por resolver el problema de la equidad.

Evaluación. La evaluación de programas y acciones es una práctica inexistente en los entes territoriales analizados. Este hecho podría ser explicado por la carencia, hasta hace muy poco, de planes de desarrollo educativo. En los establecimientos educativos existe una tradición evaluativa formal, que da cuenta de la marcha de la institución, práctica que se ha venido transformando y está siendo más participativa al hacer parte de ella la comunidad educativa.

Supervisión. Frente a esta insistencia administrativa surge una percepción negativa por parte de los actores consultados. Se considera que con la nuclearización la supervisión perdió poder y fue reemplazada por aquella. La figura del supervisor está desdibujada. En lo local, perdió poder. El papel .desempeñado de controlador del cumplimiento de las normas y la inspección formal de los planteles educativos debe ser modificado, en opinión 
de las autoridades educativas consultadas, para apoyar el proceso, prestar asesoría pedagógica y curricular a docentes y directivos. Esta situación no es clara desde las normas, pues éstas no tienen en cuenta la articulación entre la supervisión y los núcleos de desarrollo educativo.

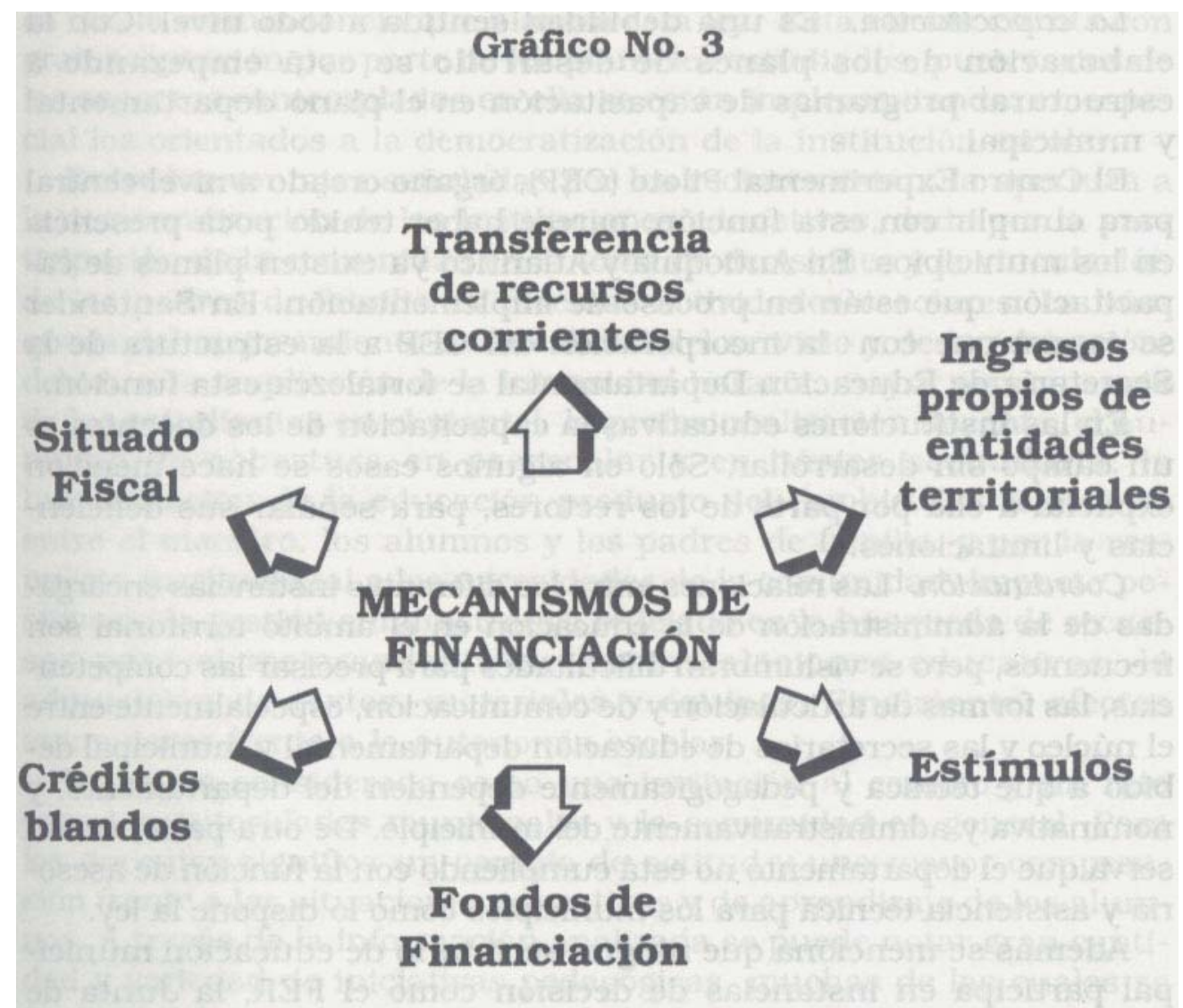

La capacitación. Es una debilidad sentida a todo nivel. Con la elaboración de los planes de desarrollo se está empezando a estructurar programas de capacitación en el plano departamental y municipal.

El Centro Experimental Piloto (CEP), órgano creado a nivel central para cumplir con esta función, parece haber tenido poca presencia en los municipios. En Antioquia y Atlántico ya existen planes de capacitación que están en proceso de implementación. En Santander se espera que con la incorporación del CEP a la estructura de la Secretaria de Educación Departamental se fortalezca esta función.

En las instituciones educativas la capacitación de los docentes es un campo sin desarrollar. Sólo en algunos casos se hace mención explicita a ella por parte de los rectores, para señalar sus deficiencias y limitaciones.

Coordinación. Las relaciones entre las diferentes instancias encargadas de la administración de la educación en el ámbito territorial son frecuentes, pero se vislumbran dificultades para precisar las competencias, las formas de articulación y de comunicación, especialmente entre el núcleo y las secretarias de educación departamental y municipal debido a que técnica y pedagógicamente dependen del departamento, y nominativa y administrativamente del municipio. De otra parte, se observa que el departamento no está cumpliendo con la función de asesoría y asistencia técnica para los municipios como lo dispone la ley. 
Además se menciona que ningún secretario de educación municipal participa en instancias de decisión como el FER, la Junta de Escalafón o en la Junta de Matrículas. Hacia el nivel central, las relaciones son aún más puntuales, dadas por contactos telefónicos y visitas de funcionarios para tratar temas administrativos y aclarativos sobre directivas producidas por el Ministerio.

Los núcleos mantienen relaciones con una amplia gama de entidades públicas y privadas, constituyéndose en un efectivo mecanismo de coordinación local. Los directores de núcleo son invitados a participar en varios comités locales de salud, bienestar social, planes de desarrollo, municipales e interinstitucionales.

El aspecto más positivo frente a los mandatarios municipales es la relevancia que le han dado a la educación. Para muchos de ellos este sector, o la educación más concretamente, se constituye en prioridad dentro de su plan de gobierno.

\subsection{La descentralización pedagógica}

La ley 115 plantea la descentralización pedagógica, proceso que se ha venido impulsando parcialmente desde la década del 70 , pero nunca con la contundencia que plantea esta ley. Esta norma cuenta con gran aceptación por parte de los planteles estudiados, pues varios de los aspectos contemplados en ella se están implementando, en especial los orientados a la democratización de la institución escolar.

Entre las ventajas señaladas por los rectores están: la apertura a la democratización de las instituciones educativas, dada por la participación de la comunidad en la toma de decisiones y la vinculación de los padres de familia en diversas actividades escolares. La búsqueda del mejoramiento de la calidad del servicio y de la educación, debido a la ampliación de la intensidad horaria, mayor permanencia de los estudiantes en el plantel, la profesionalización docente, el aumento de cobertura en preescolar y en básica secundaria, la humanización de la educación producto del cambio, las relaciones entre el maestro, los alumnos y los padres de familia, y por la respuesta institucional a las necesidades de la comunidad. Impacto positivo en la gestión administrativa reflejado en la búsqueda de recursos para el mejoramiento de las instalaciones educativas, la adquisición de textos, materiales y equipos. Finalmente, efectos animadores frente a la autonomía escolar.

La ley es considerada como una invitación al cambio y un reto para las autoridades municipales y la comunidad en general. Para los docentes significa un cambio de actitud y una mayor comprensión frente a las situaciones educativas y de aprendizaje de los alumnos. A través de la información analizada se puede notar gran cantidad y variedad de iniciativas pedagógicas, muchas de las cuales se venían adelantando con anterioridad a la ley, entre las que se destacan las relacionadas con la orientación de los procesos de aprendizaje, la organización del tiempo en el aula, la aplicación de enfoques constructivistas, los cambios en las prácticas pedagógicas, especialmente en idiomas, matemáticas y ciencias sociales, el desarrollo de metodologías participativas, el fomento a la investigación, el trabajo por proyectos, el desarrollo de proyectos comunitarios y de aula, las salidas pedagógicas, la integración de áreas y la semestralización de áreas como matemáticas y español, y el apoyo a las iniciativas de orden nacional como: la educación ambiental, el diseño curricular para la educación sexual, la implementación de la informática, la enseñanza de una lengua extranjera y los cambios en la evaluación del alumno. 
Entre las dificultades se encuentran la falta de infraestructura para atender la demanda y poder ampliar en todas las instituciones el servicio educativo básico de 9 años, la escasa capacitación y asesoría frente a las implicaciones de la ley, en especial frente al PEI, a fin de poder cumplir con los plazos asignados por el decreto 1860 de 1994. Desde el punto de vista de los docentes se considera que es una mayor exigencia laboral con la misma retribución salarial, poco estimulo a la investigación y a la capacitación docente; se reitera la falta de recursos para las instituciones y el exceso de responsabilidades sin los apoyos financieros, técnicos y pedagógicos. Otros problemas están relacionados con la resistencia a los procesos evaluativos en general, y en particular frente a la carencia de evaluación de impacto de los diferentes programas que se adelantan.

Por último, los establecimientos educativos consideran que la capacitación es una función del Estado, y en relación con los mecanismos de financiación han buscado apoyo en FLNDETER y en el FIS para la aprobación de los proyectos presentados, pero no han logrado apoyo. Actitud frente a la cual ha habido una gran queja, debido a la cantidad de tiempo, energía y recursos invertidos en esta dinámica. Consideran que hay exceso de burocracia y lentitud en el proceso de estudio y aprobación de los proyectos.

\subsection{La descentralización fiscal}

Como se puede deducir de lo planteado hasta ahora, uno de los mayores obstáculos a la descentralización está en sus aspectos financieros, siendo lo más preocupante la escasez de recursos para atender las responsabilidades asignadas. Consideran los actores consultados que hubo fallas en la elaboración de la fórmula de base para la asignación de recursos, a lo que se suma otra dificultad de carácter jurídico, como el fallo de la Corte Constitucional, que obliga a vincular en el menor tiempo posible a los docentes por contrato a las plantas de personal. Hay razones también de tipo administrativo, ocasionadas por la demora en los giros de los recursos del situado fiscal y los recortes que se vienen dando con efectos preocupantes para 1996.

Frente a esta situación, considerada grave, los alcaldes plantean estrategias para reducir el gasto y para incrementar los ingresos municipales. Dentro de las primeras se encuentra la reducción de la nómina y los gastos de funcionamiento, realizar una mejor planeación, racionalizar el gasto, capacitar a los funcionarios municipales e introducir prácticas de gerencia moderna. Parece ser que la escasez de recursos es consecuencia de un manejo ineficiente de éstos, lo que significa que la solución no sólo se encontraría en allegar más recursos sino en invertir mejor los que se tienen, y así ser más eficientes. Dentro de las opciones para incrementar ingresos están la adopción de medidas administrativas y financieras, tales como mejorar el recaudo de impuestos, concientizar a la población de la importancia de pagarlos, sistematizar el área de las finanzas, ordenar y programar los ingresos, reajustar tarifas de servicios públicos, actualizar el catastro, disminuir la transferencia de los recursos al Concejo Municipal, crear sistemas de fiducia para el pago de impuestos y hacer uso de los mecanismos de cofinanciación, y pensar en estrategias como reubicación de docentes y veeduría ciudadana.

En relación con la cofinanciación se observa que este mecanismo se ha extendido bastante entre los municipios y los departamentos, existiendo proyectos de cofinanciación con FINDETER. En nueve de los municipios analizados se está utilizando este mecanismo, principalmente para construcciones. Para el pago de docentes, becas y adquisición de textos, se está trabajando en coordinación con el FIS, lo cual es bueno en teoría pero difícil en la práctica. Los recursos del FIS, expresan algunos de los actores, 
están comprometidos en iniciativas parlamentarias y por la burocracia del mismo FIS, lo que ha generado gran tensión entre las autoridades locales y los funcionarios de este organismo.

La descentralización y la insuficiencia de recursos ha potenciado la iniciativa local para tratar de superar la dependencia del nivel central, como consecuencia del agotamiento frente a ciertos procesos. Trece municipios han presentado propuestas a varías entidades públicas y privadas, y en dos casos se está organizando un Banco de Proyectos Municipal. Existe poco conocimiento y utilización del Banco Nacional de Proyectos del Departamento Nacional de Planeación. Sólo dos casos se encontraron orientados en esta dirección. La banca comercial ha sido utilizada por tres municipios para obtener recursos. Un mecanismo que está por desarrollarse es la realización de convenios con el sector privado. Pocos municipios mencionan la utilización de este mecanismo.

Las restricciones fiscales mencionadas y sus alternativas de solución requieren desarrollar y fortalecer el papel de asesoría y asistencia a los departamentos y, municipios como lo dispone la ley.

En síntesis, se puede observar un gran impulso desde las localidades para llevar a cabo el proceso de descentralización de la educación y una actitud positiva frente al manejo autónomo de los problemas del sector, aún cuando se es consciente de que hay mucho camino por recorrer.

\section{La descentralización desde el punto de vista de los establecimientos educativos}

La incidencia de la descentralización a partir del análisis de las instituciones educativas estudiadas se concreta en:

1) La autonomía de la institución entendida como la competencia para definir políticas internas, orientar y desarrollar acciones a partir del Proyecto Educativo Institucional, la reorientación metodológica en torno a prácticas docentes que permitan una participación más activa de los alumnos en su proceso de aprendizaje, en la vida escolar, en la toma de decisiones y en la resolución de conflictos.

2) El mejoramiento de la calidad. Busca la articulación del conocimiento universal con el contexto local para dar respuesta a las necesidades del entorno socioeconómico y cultural, e innovar para lograr mejores procesos de aprendizaje y orientar nuevas formas de capacitación.

3) Ampliación de la cobertura al ubicar a las instituciones en capacidad de dar respuesta a la demanda, y por la obligatoriedad de la educación básica de nueve años.

4) Fortalecimiento de La participación comunitaria en la vida institucional educativa al participar en el gobierno escolar y en la construcción del PEI.

5) Liderazgo de la Dirección en pro del mejoramiento escolar y de la capacidad de resolver problemas y la generación de mecanismos para la toma de decisiones. Este liderazgo se ejerce dentro y fuera de la institución educativa. Internamente en cuanto al clima organizacional que se construye, y externamente mediante la forma como se toman las decisiones y se desarrollan procedimientos para implementar programas, solucionar conflictos, superar obstáculos en el proceso y establecer contactos con otras organizaciones, autoridades municipales, principalmente del sector educativo para conseguir apoyo financiero, técnico, recibir asesoría y orientación. 
6) La articulación con otras instancias conservando la autonomía de la institución para poder asumir las responsabilidades propias de su competencia; desarrollar su proyecto y, lo que ha sido hasta el momento una práctica inexistente, planificar su presupuesto.

Los establecimientos educativos han avanzado en el desarrollo de su Proyecto Educativo Institucional, punto de partida para la búsqueda de identidad y legitimidad de la institución escolar, la participación de la comunidad y la democratización en la toma de decisiones. En experiencias innovadoras estudiadas, el proyecto institucional ha tenido como referencia diagnósticos realizados tanto por la misma institución educativa como por su localidad.

Los actores consultados en las instituciones escolares han manifestado que existe una gran aceptación de la descentralización en cuanto a la autonomía, pero es fuerte el cuestionamiento frente a la asignación de responsabilidades sin recursos, lo que la hace percibir como una estrategia eminentemente financiera ante la incapacidad del Estado a nivel central para resolver estos problemas, que se los entrega a otros sin las condiciones para asumirlas. Se reconoce que ha facilitado la adquisición de recursos físicos, que ha permitido la ampliación de la planta de personal cuando se requiere y la solución de algunas deficiencias en la planta física. Los padres consideran que la posibilidad de buscar solución a los problemas en una instancia más cercana, como la del municipio, es una ventaja. Sin embargo, ven la descentralización como un proceso que va en camino y opinan que hay mucho por recorrer, sobre todo desde el aspecto presupuestal.

La potencialidad descubierta por las instituciones educativas ha sido aprovechada para la autodeterminación de la vida institucional dada la iniciativa de la comunidad educativa al impulsar y desarrollar acciones en pro de la satisfacción de necesidades colectivas y de resolver los problemas y conflictos, fortaleciéndose así, de paso, el espíritu democrático y participativo. El hecho más importante que puede registrarse en torno a la incidencia de la descentralización en las instituciones es, entonces, el de sentirse mayores de edad en la búsqueda de soluciones a los problemas educativos y en su relación con la comunidad y otras instituciones.

Las instituciones estudiadas consideradas exitosas, según los diferentes actores consultados, lo son: por su manejo administrativo, por la calidad de los maestros, por las posibilidades de actualización que se brindan, por su infraestructura física, por la participación colectiva en actos socioculturales, por el nivel de formación que dan a los niños y jóvenes, por la calidad académica de los estudiantes, por el buen trato de los docentes y por la formación integral que reciben. (Véase cuadro No. 1).

Pese a que la descentralización, desde el plano de las instituciones, es percibida positivamente, se señalan algunos obstáculos que es necesario superar, tales como la influencia de una política no muy adecuada en la administración del sector educativo, razón por la cual se siente la necesidad de influir políticamente en las decisiones del municipio para lograr conquistas en el sector educativo. Esta "tradición política" conduce a prácticas clientelistas para el nombramiento de personas en cargos oficiales, sin que el sector educativo escape a este problema, lo cual se percibe en el favoritismo frente a las instituciones 0 en el nombramiento de personas inadecuadas para desempeñar actividades educativas, con sentido pedagógico y comunitario.

Otro obstáculo percibido es el relacionado con la organización de la administración. Las instituciones no logran aclarar cuál es la línea de responsabilidad, cómo establecer un 
acercamiento al municipio, ni cómo recibir una asesoría. Las instituciones sienten que se están reorganizando internamente en torno a la nueva ley, pero no ocurre lo mismo en el orden local.

Un tercer obstáculo es el relacionado con el presupuesto. Los municipios aún no tienen la capacidad para asumir las responsabilidades asignadas, ni para responder a las demandas educativas de su localidad.

Pese a estos obstáculos que constriñen las posibilidades prácticas de implementar la ley con todas sus bondades, los actores de los establecimientos educativos (padres, alumnos y docentes) manifiestan que es un camino que debe proseguirse superando los obstáculos de orden político, administrativo y fiscal.

En los últimos años, y en especial después de la promulgación de la nueva Carta Política, se han venido experimentando transformaciones culturales importantes que se manifiestan en la concientización de amplios sectores de la población sobre sus derechos y deberes, y en la apropiación de conceptos tales como participación y autonomía que conducen a conocimiento y aceptación de la responsabilidad colectiva frente a la construcción de un futuro mejor, cuestionamientos y reflexiones que pueden apoyar el proceso de descentralización.

\section{Variables de éxito}

\section{(Cuadro No. 1)}

- Las variables que en opinión de los directivos docentes, maestros, alumnos y padres, definen una institución exitosa, son:

- Responsabilidad institucional y personal

- Buen nivel académico de los docentes

- Evaluación permanente

- Amor y entrega a la institución

- Adecuada dirección y buena administración

- Concertación entre los diferentes estamentos

- Existencia de programas de bienestar estudiantil

- Formación moral y ética

- Desarrollo de actividades culturales

- Buen material didáctico

- Buen mantenimiento de las instalaciones y equipos

- Buena planta física

- Proyección a la comunidad

- Participación de la comunidad

- Buenas relaciones humanas

- Testimonio y calidad de egresados

- Planta docente completa desde el comienzo de año

- Utilización de los recursos que ofrece el medio

- Creación de equipos interdisciplinarios

- Despertar interés por la investigación

- En lo académico, una preocupación mayor por el desarrollo de competencias más que de contenidos. 


\section{Estudios de caso}

Para sustentar empíricamente lo expresado frente a los hallazgos, se seleccionaron tres del total de los municipios estudiados. Uno en cada departamento, con sus respectivos establecimientos, considerados a partir del análisis de la información como experiencias que permitan explicitar el modelo normativo de descentralización con sus ventajas y desventajas. Presentarán: una mejor gestión, un manejo con mayor solvencia de los problemas para la administración del servicio, de los establecimientos y de los docentes: respuestas más efectivas y eficientes frente a los problemas de cobertura y calidad; mejores procesos de interacción escuela-comunidad y espacios de participación. Permiten observar con ello una "nueva" cultura ciudadana y una actitud positiva frente al proceso, como también, el desarrollo de iniciativas lideradas por las autoridades locales para facilitar el cambio.

Además, los tres casos presentan diferentes grados de desarrollo en el contexto nacional, lo que apoya la afirmación ya planteada, de que un proceso de cambio como el pretendido con la descentralización es un proceso a largo plazo, y que su asimilación y concreción no pueden ser uniformes en un país pluricultural como Colombia, con tan acentuadas diferencias de desarrollo económico y social entre sus entes territoriales.

\subsection{El caso de Bucaramanga}

\section{Características generales del municipio}

La ciudad de Bucaramanga es la capital del departamento de Santander. Cuenta con una población de un poco más de 400.000 habitantes, incluida el área metropolitana ${ }^{7}$, según el censo de 1993. Bucaramanga es una ciudad de tamaño intermedio. La población es eminentemente urbana, localizándose en la cabecera municipal el $96.9 \%$ de los habitantes. Su extensión es de $165 \mathrm{kms}$. Cuadrados. Se encuentra asentada en un terreno montañoso bastante quebrado, poco fértil y afectado por una acentuada erosión, producto, entre otras cosas, del acelerado y desordenado proceso de urbanización.

La base económica del municipio está compuesta por el sector industrial y de servicios. Un rasgo característico es la presencia de una alta proporción de población ubicada en el sector informal, producto de la incapacidad de los sectores tradicionales para absorber el total de la población económicamente activa. La tasa de desempleo es alta, está por encima del promedio nacional.

Para 1993 se calculó el desempleo en un 13.1\%, siendo el nacional de $9.9 \%$.

La cobertura de los servicios públicos de acueducto, alcantarillado y aseo hacen de Bucaramanga una ciudad excepcional dentro del concierto nacional, pues alcanza porcentajes de cubrimiento del $100 \%, 99 \%$ y $100 \%$ respectivamente, lo que contribuye a que las condiciones de vida de la población pobre sean cualitativamente superiores a las de otras zonas urbanas del país. Se calcula en un $22 \%$ la población con Necesidades Básicas Insatisfechas (NBI), y en 6.3\% los hogares en condiciones de miseria.

Con relación al sector educativo se registra déficit de cupos en los campos de la básica secundaria y de la educación superior. Las tasas de escolarización para 1993 se estimaban en $32.6 \%$ para el preescolar, en $97.6 \%$ para la básica primaria y en $89.4 \%$ para la secundaria.

\footnotetext{
${ }^{7}$ Conforman el área metropolitana los municipios de Girón, Floridablanca y Piedecuesta 
El $94.5 \%$ de los docentes que laboran en el municipio son de carácter nacional, pagados por el FER, el $2.5 \%$ por el departamento y el $3 \%$ por el municipio. El número de establecimientos de preescolar asciende a nueve, los de la educación básica primaria son 112 y los de la básica secundaria 17. Existen cuatro núcleos de desarrollo educativo, según los datos suministrados por la Secretaría de Educación.

Cuadro No.1

Distribución del Presupuesto

\begin{tabular}{|l|l|l|l|l|l|l|l|}
\hline AÑO & $\begin{array}{l}\text { PRESUPUESTO } \\
\text { TOTAL }\end{array}$ & EDUCACION & $\%$ & NÓMINA & $\%$ & DOTACION & $\%$ \\
\hline $\mathbf{1 9 8 9}$ & 5.415 .758 .635 & 351.331 .419 & 6.4 & 170.331 .419 & 48.4 & 181.000 .000 & 51.6 \\
\hline $\mathbf{1 9 9 0}$ & 5.204 .348 .502 & 321.095 .930 & 6.2 & 207.473 .023 & 64.6 & 113.622 .907 & 35.4 \\
\hline $\mathbf{1 9 9 1}$ & 8.432158 .409 & 545.437 .855 & 6.5 & 265.433 .855 & 48.7 & 280.004 .000 & 51.3 \\
\hline 1992 & 11.911 .505 .291 & 963.038 .098 & 8.0 & 345.038 .098 & 35.8 & 618.000 .000 & 64.2 \\
\hline 1993 & 21.567 .743 .040 & 1.257 .634 .706 & 5.8 & 247.634 .706 & 19.7 & 1.010 .000 .000 & 80.3 \\
\hline
\end{tabular}

Fuente: Secretaria de Educación

El presupuesto del municipio de Bucaramanga se ha venido incrementando de modo significativo en los últimos cuatro años. De 1989 a 1993, se incrementó en un 298\%. Los incrementos han sido particularmente importantes a partir del año 1992. Con relación al sector educativo, éste también ha ido aumentando de modo importante al incrementarse de 1989 a 1993 en un 257.9\%. La participación del sector educativo dentro del presupuesto global ha pasado de un $6.4 \%$ en 1989 a un $8.0 \%$ en 1992, observándose una baja en 1993 cuando el porcentaje se ubica en un 5.8\%. El aumento del presupuesto municipal está estrechamente relacionado con el incremento en las transferencias, estipulado por el decreto-ley 077 de 1987 y posteriormente por la ley 60 de 1993.

La descentralización de la educación en el municipio se presenta en el siguiente cuadro, que resume las características en los aspectos administrativo, fiscal y pedagógico.

De la lectura del cuadro se desprende una actitud positiva frente a la descentralización y una dinámica político-administrativa favorable, factores que, unidos a un positivo balance presupuestal, son de gran importancia para asumir eficaz y eficientemente la solución de los problemas educativos desde el municipio.

Para conocer el financiamiento de las instituciones y sus relaciones con el municipio y la descentralización se estudiaron dos instituciones educativas reconocidas como exitosas: El Instituto Maiporé y la Escuela María Cano.

El Instituto "Maiporé" es una institución oficial con dos jornadas y presta el servicio de la básica secundaria. Desde 1992 se adicionó la media vocacional. Para efectos de la investigación se tomó la jornada de la tarde. Del año 89 al 90, año en que se municipalizó la educación, hubo un aumento de maestros pero también de alumnos. La repitencia es alta, se mantiene un promedio del $23 \%$, bajando al $14 \%$ en 1990 y aumentando al $31 \%$ en 1991. La deserción, como muestra el cuadro No. 3, tiende a aumentar. Podría decirse que lo "exitoso" no tiene en cuenta estos fenómenos o que, por el contrario, conduce a incrementar los índices de deserción y repitencia, aspecto sobre el cual vale la pena profundizar. Los maestros son todos pagados por el FER, excepto tres que aporta el municipio en 1992, cuando se inicia la educación media vocacional. 


\section{Municipio de Bucaramanga}

\begin{tabular}{|c|c|c|}
\hline ADMINISTRATIVA & FISCAL & PEDAGÓGICA \\
\hline $\begin{array}{l}\text { - Credibilidad en la secretaría } \\
\text { De educación } \\
\text {-Buena administración de los } \\
\text { Establecimientos educativos. } \\
\text { Pero déficit de cupos. } \\
\text {-Existe voluntad política del } \\
\text { alcalde y del Consejo Municipal } \\
\text { para hacer de la educación un } \\
\text { polo de desarrollo. } \\
\text {-Capacidad para resolver los } \\
\text { problemas fiscales y de manejo } \\
\text { de personal docente, pero } \\
\text { poca confianza por parte del } \\
\text { municipio en las oficinas del } \\
\text { FER y de escalafón, como } \\
\text { apoyo. } \\
\text {-El municipio cuenta con plan } \\
\text { de desarrollo educativo basado } \\
\text { en un diagnóstico participativo. } \\
\text { El plan contempla un programa } \\
\text { de actualización y capacitación } \\
\text { docente, con el apoyo de } \\
\text { organizaciones no } \\
\text { gubernamentales. } \\
\text {-Existe buena coordinación } \\
\text { entre las instancias del sector } \\
\text { educativo, con otras } \\
\text { instituciones gubernamentales y } \\
\text { no gubernamentales, pero con } \\
\text { la Secretaría de Educación } \\
\text { Departamental. } \\
\text {-Existen bunas relaciones con } \\
\text { los docentes y preocupación } \\
\text { por su bienestar. } \\
\text {-Se vienen adelantando } \\
\text { contratos con la empresa } \\
\text { privada para el desarrollo de } \\
\text { programas. El municipio brinda } \\
\text { apoyo logístico y el sector } \\
\text { privado ejecuta el programa. }\end{array}$ & $\begin{array}{l}\text {-La educación es asumida como } \\
\text { una inversión. } \\
\text {-Se ha logrado ampliar la base } \\
\text { de ingresos con recursos de la } \\
\text { Nación, del municipio y de } \\
\text { proyectos apoyados unos por } \\
\text { FINDETER y otros por } \\
\text { organizaciones internacionales. } \\
\text { Se han utilizado los bonos de la } \\
\text { deuda pública y los mecanismos } \\
\text { existentes para allegar recursos } \\
\text { de Planeación Nacional a través } \\
\text { de proyectos inscritos en el } \\
\text { Banco de Proyectos. } \\
\text {-Se han utilizado plazas } \\
\text { docentes cofinanciadas y las } \\
\text { becas PACES } \\
\text { subvencionar para } \\
\text { cooperativos. colegios } \\
\text {-No existen dificultades de tipo } \\
\text { financiero porque se busca } \\
\text { solucionar los problemas. Pero } \\
\text { han tenido dificultades con el } \\
\text { FIS para el desarrollo de } \\
\text { proyectos cofinanciados. }\end{array}$ & $\begin{array}{l}\text {-Se han estimulado La iniciativa } \\
\text { y la creatividad a través De la } \\
\text { capacitación del maestro y se } \\
\text { ha generado participación de la } \\
\text { Comunidad en los asuntos } \\
\text { Educativos y de los padres de } \\
\text { Familia en la institución. } \\
\text {-La capacitación del docente } \\
\text { Se orienta hacia el conocimiento } \\
\text { de Tecnologías modernas para } \\
\text { lograr mejores aprendizajes en } \\
\text { los alumnos. } \\
\text {-Se han creado mecanismos } \\
\text { para mejorar la administración } \\
\text { de las instituciones educativas y } \\
\text { brindar autonomía para } \\
\text { adecuación al contexto. } \\
\text {-La ley 115 ha democratizado } \\
\text { las instituciones y ha permitido } \\
\text { efectuar ajustes curriculares } \\
\text { acorde con las necesidades } \\
\text { culturales, científicas } \\
\text { tecnológicas del contexto y } \\
\text { relacionar lo local con lo } \\
\text { universal. dificultades para } \\
\text {-Existen don dornada única } \\
\text { implementar la jornada } \\
\text { por infraestructura. } \\
\text {-Se ha estimulado la } \\
\text { investigación. } \\
\text {-Las instituciones educativas } \\
\text { definen sus políticas a partir de } \\
\text { las necesidades tanto } \\
\text { institucionales } \\
\text { comunitarias. }\end{array}$ \\
\hline
\end{tabular}




\section{Cuadro No. 2}

\begin{tabular}{|c|c|c|c|c|c|c|c|c|c|c|c|c|c|c|c|c|}
\hline \multirow[t]{3}{*}{ Año } & \multirow{2}{*}{\multicolumn{3}{|c|}{ NIVEL }} & \multirow{2}{*}{\multicolumn{2}{|c|}{ JORNAD }} & \multicolumn{6}{|c|}{ FINANCIACION } & \multirow{2}{*}{\multicolumn{5}{|c|}{ ALUMNOS }} \\
\hline & & & & & & & & MAES & & & $\mathrm{DOC}$ & & & & & \\
\hline & $\mathrm{BP}$ & BS & $\mathrm{MV}$ & MAÑ & TAR & FER & DEP & MUN & OTRO & TOTAL & No & TOTAL & DES & REPIT & OFERTA & DEMANDA \\
\hline 89 & & $\mathrm{X}$ & & & $\mathrm{X}$ & 11 & & & & 11 & 1 & 297 & 8 & 67 & 297 & 700 \\
\hline 90 & & $\mathrm{X}$ & & & & 15 & & & & 15 & 1 & 367 & 7 & 53 & 367 & 542 \\
\hline 91 & & $\mathrm{X}$ & & & & 16 & & & & 16 & 1 & 395 & 25 & 125 & 395 & 498 \\
\hline 92 & & $\mathrm{X}$ & & & & 15 & & & & 15 & 1 & 339 & 38 & 97 & 339 & 294 \\
\hline & & & $\mathrm{X}$ & & & 5 & & 3 & & 8 & 1 & & 7 & 27 & 52 & 52 \\
\hline 93 & $\mathrm{X}$ & & & & & 21 & & & & 21 & 1 & 410 & 29 & 97 & 410 & 410 \\
\hline & & & $\mathrm{X}$ & & & -6 & & & & -6 & 1 & 59 & 5 & 13 & 59 & 59 \\
\hline
\end{tabular}

Fuente: Formularios DANE C-600

Cuadro No. 3

\begin{tabular}{|c|c|c|c|c|c|}
\hline AÑO & POBLACION & RELACION & DISERCION & REPITENCIA & DEMANDA \\
& ATENDIDA & DOC - ALUM & PORCENTAJE & PORCENTAJE & OFERTA \\
\hline $\mathbf{1 9 8 9}$ & 297 & 27 & 2.7 & 22.5 & 2.3 \\
\hline $\mathbf{1 9 9 0}$ & 367 & 24.5 & 1.9 & 14.4 & 1.4 \\
\hline $\mathbf{1 9 9 1}$ & 395 & 24.6 & 6.3 & 31.6 & 1.2 \\
\hline $\mathbf{1 9 9 2}$ & 339 & 22.6 & 11.2 & 28.6 & 0.86 \\
\hline $\mathbf{1 9 9 3}$ & 410 & 19.5 & 7.07 & 23.6 & 1 \\
\hline & 59 & 22.6 & 8.5 & 22.0 & 1 \\
\hline
\end{tabular}

La Concentración "MARÍA CANO", es una institución oficial, con dos jornadas, una en la mañana y una en la tarde, en básica primaria. Los maestros son pagados por el FER, tres adicionales que se vincularon en 1993 los paga el municipio. El número de maestros permanece constante hasta 1993, año en el cual se vinculan tres más, y curiosamente baja el número de alumnos.

\section{Cuadro No. 4}

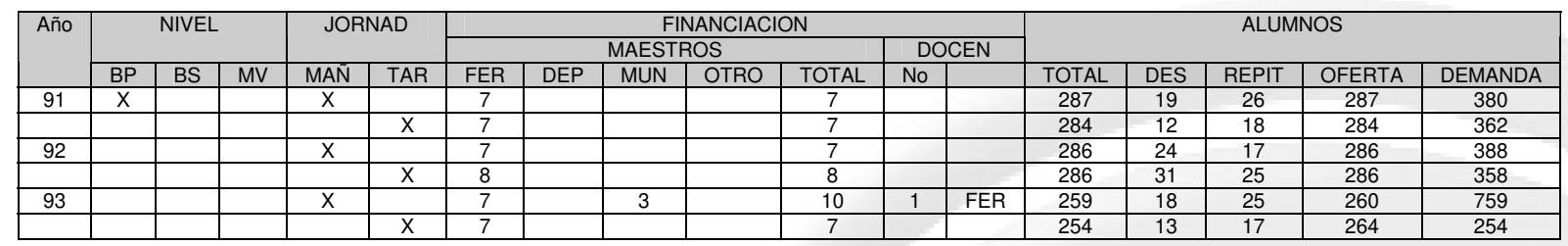

Fuente: Formulario C-600 DANE

La repitencia y deserción, aunque muestran una tendencia a bajar, son altas aunque significativamente inferiores al colegio anterior, lo cual podría indicar que estos fenómenos son más graves en secundaria que en primaria. La comunidad educativa reconoce que el establecimiento cuenta con una planta de personal adecuada. El número de alumnos por docentes muestra una de las proporciones más altas, comparativamente, con las otras instituciones analizadas, aunque ésta tienda a disminuir.

En las dos instituciones se pueden registrar dinámicas que señalan procesos autónomos e iniciativa para la solución de problemas, como también procesos de democratización en la organización escolar. Maestros, padres y alumnos reconocen y comparten tanto los objetivos como las actividades de la institución. Manifiestan que el currículo se enmarca dentro de los parámetros de la Ley General de Educación. La percepción de la descentralización es heterogénea tanto en su aceptación como en cuanto al conocimiento que se llene de la misma. El Instituto Maiporé reconoce que la descentralización le ha traído beneficios como son la ampliación de la planta docente, 
mejoramiento de la planta física y la atención de necesidades prioritarias. Por el contrario, en la escuela Maria Cano sólo los docentes conocen algo sobre la descentralización y la valoran negativamente, porque consideran que hay mal manejo de los recursos por parte de los políticos y que además son insuficientes.

\subsection{El caso de Rionegro}

\section{Características generales del municipio}

El municipio de Rionegro está localizado en el oriente del departamento de Antioquia, a 40 kilómetros de la ciudad de Medellín, su capital. Es uno de los municipios más antiguos y de mayor renombre en el departamento, con una población total de más de 100.000 habitantes, de los cuales el $61 \%$ están en la zona urbana.

Rionegro, por su privilegiada localización geográfica, su dinamismo económico y cultural, es considerado como uno de los principales polos de desarrollo del departamento de Antioquia. Ha experimentado una transformación importante en las formas de producción. De una población dedicada con exclusividad a actividades artesanales y de comercio, se ha pasado a actividades agroindustriales, industriales y comerciales a lo cual han contribuido, muy seguramente, la presencia del aeropuerto internacional, utilizado por la ciudad de Medellín, y la existencia de la zona franca. Además, cuenta con uno de los mejores sistemas de comunicación nacional.

\section{Cuadro No. 5}

\begin{tabular}{|c|c|c|c|c|c|c|}
\hline AÑO & JORNADA & MATRICULA & $\begin{array}{c}\text { RELACION } \\
\text { DOC - ALUM }\end{array}$ & $\begin{array}{c}\text { DESERCION } \\
\text { PORCENTAJE }\end{array}$ & $\begin{array}{c}\text { REPITENCIA } \\
\text { PORCENTAJE }\end{array}$ & $\begin{array}{c}\text { DEMANDA } \\
\text { OFERTA }\end{array}$ \\
\hline $\mathbf{1 9 9 1}$ & Mañana & 287 & 41 & 6.6 & 9 & 1.3 \\
\hline & Tarde & 284 & 40.6 & 4.2 & 6.3 & 1.2 \\
\hline $\mathbf{1 9 9 2}$ & Mañana & 286 & 40.8 & 8.4 & 6 & 1.3 \\
\hline & Tarde & 286 & 35.7 & 10.8 & 8.7 & 1.3 \\
\hline $\mathbf{1 9 9 3}$ & Mañana & 259 & 25.9 & 7 & 9.6 & 1 \\
\hline & Tarde & 254 & 36.3 & 5.11 & 6.7 & 0.96 \\
\hline
\end{tabular}

En 1993, según datos de la Secretaría de Educación Municipal, Rionegro contaba, entre el sector oficial y el privado, con 27 establecimientos en preescolar y 54 de básica primaria, 18 de básica secundaria y media vocacional, con un total de 325 docentes en preescolar y básica primaria, 379 de básica secundaria y media vocacional, 10.674 alumnos en preescolar y básica primaria y 8.736 alumnos entre básica secundaria y media vocacional.

La mayoría de los docentes que laboran en los establecimientos educativos son pagados por el FER. El municipio paga sólo el 12.3\% del total de los docentes.

El presupuesto del municipio de Rionegro se ha ido incrementando en un $212 \%$ de 1990 a $1993^{8}$.

La percepción de la descentralización en el municipio se puede apreciar en el siguiente cuadro, el cual muestra el compromiso frente a este proceso:

\footnotetext{
${ }^{8}$ Ultimo dato reportado para el estudio.
} 


\section{Descentralización}

\begin{tabular}{|c|c|c|}
\hline ADMINISTRATIVA & FISCAL & PEDAGÓGICA \\
\hline $\begin{array}{l}\text {-Asumió la educación en } 1991 \\
\text { ajustándose a la ley } 29 \text { de } \\
1989 \text {. } \\
\text {-La administración de los } \\
\text { planteles ha sido relativamente } \\
\text { fácil. Se cuenta con personal } \\
\text { directivo muy calificado. } \\
\text {-Hay exceso de burocracia lo } \\
\text { cual se piensa llevar a cabo una } \\
\text { reforma administrativa. } \\
\text {-En Rionegro se han } \\
\text { desarrollado } \\
\text { autónomos para la solución de } \\
\text { problemas locales. } \\
\text {-Existen adecuados niveles de } \\
\text { coordinación entre el municipio } \\
\text { y las instituciones educativas a } \\
\text { través de los núcleos, aunque } \\
\text { no sucede lo mismo entre } \\
\text { municipio y departamento. } \\
\text {-No existen problemas con los } \\
\text { docentes. Todos cumplen los } \\
\text { requisitos del escalafón y se } \\
\text { tiene una política "agresiva" de } \\
\text { capacitación. }\end{array}$ & $\begin{array}{l}\text {-No existen dificultades de tipo } \\
\text { financiero, aunque no se tiene } \\
\text { todo lo que se necesita, se han } \\
\text { realizado esfuerzos para } \\
\text { aumentar los ingresos del } \\
\text { municipio. } \\
\text {-Se han realizado grades } \\
\text { inversiones en educación, pues } \\
\text { no es factible reducir estos } \\
\text { gastos. } \\
\text {-Se han realizado convenios con } \\
\text { FINDETER para la construcción } \\
\text { y remodelación de planteles. } \\
\text { Tienen recursos por becas } \\
\text { PACES. } \\
\text {-Se está motivando a los } \\
\text { directivos docentes para que } \\
\text { presenten proyectos al } \\
\text { Departamento Nacional de } \\
\text { Planeación. departamento de } \\
\text {-Con el depar } \\
\text { Antioquia se tiene convenio para } \\
\text { ampliación de cobertura y de } \\
\text { grado cero. } \\
\text {-Se han realizado convenios de } \\
\text { prestación de servicios con } \\
\text { algunos colegios privados para } \\
\text { la prestación de la educación } \\
\text { especial, protección de } \\
\text { menores, y la básica primaria. } \\
\text {-El sector privado se ha } \\
\text { vinculado con algunos planteles } \\
\text { para financiar y cofinanciar } \\
\text { algunos proyectos en educación } \\
\text { física, recreación y deporte. }\end{array}$ & 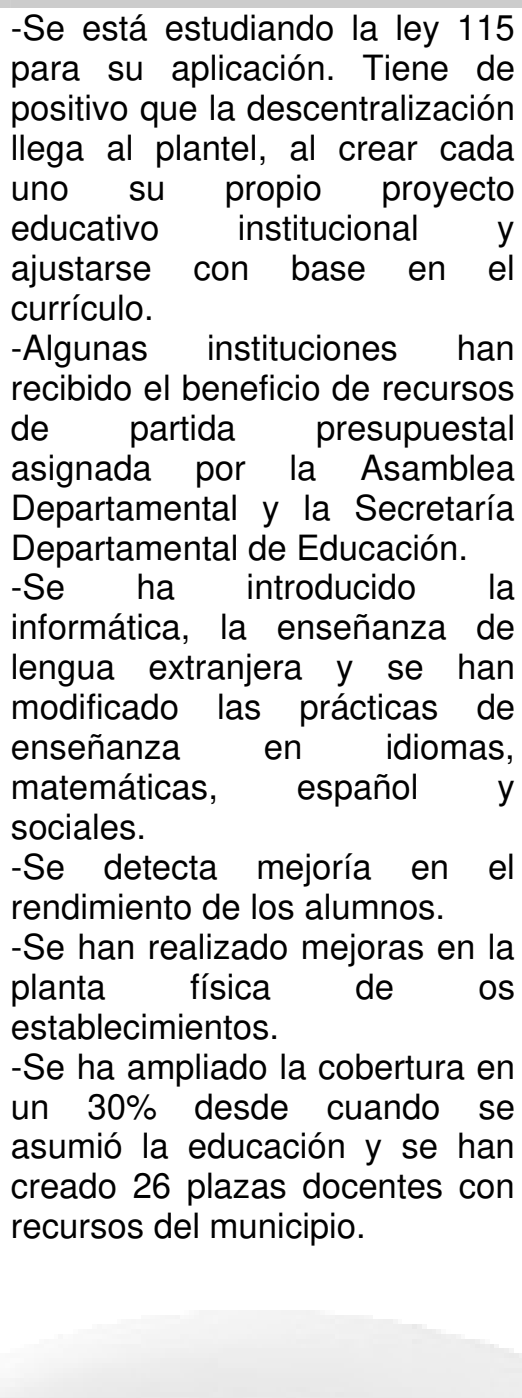 \\
\hline
\end{tabular}

Las instituciones estudiadas fueron: el Instituto Pascuala Muñoz de Córdoba y el Instituto Josefina Muñoz.

El Colegio "Pascuala Muñoz", de Rionegro, es una institución oficial, se ha analizado la jornada de la mañana, que es de básica primaria. El número de maestros se mantiene constante desde 1989 y todos pertenecen a la nómina del Fondo Educativo Regional (FER).

La población estudiantil de 1989 a 1990 aumentó en un 59\%, manteniendo el mismo número de docentes, siendo así que la relación maestro-alumno es de 18.6 a 31. La deserción es alta y se ha ido incrementado. No sucede lo mismo con la repitencia, la cual ha disminuido. 


\section{Cuadro No. 6}

\begin{tabular}{|c|c|c|c|c|c|c|c|c|c|c|c|c|c|c|c|c|c|}
\hline \multirow[t]{3}{*}{ Año } & \multirow{2}{*}{\multicolumn{3}{|c|}{ NIVEL }} & \multirow{2}{*}{\multicolumn{2}{|c|}{ JORNAD }} & \multicolumn{7}{|c|}{ FINANCIACION } & \multirow{2}{*}{\multicolumn{5}{|c|}{ ALUMNOS }} \\
\hline & & & & & & & & MAES & & & & SEN & & & & & \\
\hline & BP & BS & MV & MAÑ & TAR & FER & DEP & MUN & OTRO & TOTAL & No & & TOTAL & DES & REPIT & OFERTA & DEMANDA \\
\hline 89 & $\mathrm{X}$ & & & $\mathrm{X}$ & & 11 & & & & 11 & 1 & FER & 205 & 29 & 10 & 270 & 205 \\
\hline 90 & & & & & & 11 & & & & 11 & 1 & FER & 345 & 29 & 9 & 450 & 345 \\
\hline 91 & & & & & & 11 & & & & 11 & 1 & FER & 350 & 30 & 8 & 450 & 350 \\
\hline 92 & & & & & & 11 & & & & 11 & 1 & FER & 334 & 31 & 8 & 450 & 334 \\
\hline 93 & & & & & & 11 & & & & 11 & 1 & FER & 325 & 44 & 6 & 450 & 325 \\
\hline
\end{tabular}

Fuente:formularios DANE C-600

La institución Josefina Muñoz, es un establecimiento oficial con dos jornadas en básica secundaria. Para el análisis se tuvo en cuenta la jornada de la mañana. La relación docente-alumno es baja. La deserción es estable y la repitencia, de manera preocupante, está en ascenso. Los docentes en su totalidad son pagados por el FER.

Las instituciones presentadas han desarrollado formas participativas de organización escolar desde diferentes ángulos: En el Pascuala Muñoz, desarrollando programas de participación comunitaria con los padres de familia y en el Josefina Muñoz, invitando a los padres de familia a participar de las actividades institucionales. Ambas instituciones reconocen beneficios y desventajas del proceso de descentralización. Entre los beneficios figuran: la mayor autonomía que tiene ahora la institución, lo cual facilita la toma de decisiones, la adquisición de recursos físicos y el cubrimiento de la planta de personal. Entre las dificultades, están: la falta de organización de los municipios para responder por la educación, la carencia de dotación y de presupuesto que, según las instituciones, se genera en la administración. Todos manifiestan tener conocimiento de la descentralización, pero solicitan mayor asesoría tanto del municipio como del departamento.

\subsection{El caso de Baranoa}

\section{Características generales del municipio}

El municipio de Baranoa, creado en 1856, está ubicado en el departamento del Atlántico, a 22 kilómetros de Barranquilla, sobre la vía denominada "Carretera de la Cordialidad", que conduce a Cartagena y al interior del país. De acuerdo con el censo de población de 1993, su población asciende a 38.095 habitantes, de los cuales el $71.7 \%$ se localiza en la cabecera municipal y el $28.3 \%$ en la zona rural. Tiene una tasa de crecimiento exponencial dE 1.52, según los datos suministrados por el municipio a FINDETER.

Cuadro No. 10

\section{EVOLUCIÓN PRESUPUESTO DESTINADO A EDUCACIÓN EN EL MUNICIPIO DE BARANOA}

\begin{tabular}{|c|c|c|c|c|}
\hline AÑO & TOTAL & $\begin{array}{c}\text { PRESUPUESTO } \\
\text { EDUCACION }\end{array}$ & $\begin{array}{c}\text { PRESUPUESTO } \\
\text { EDUCACION }\end{array}$ & $\begin{array}{c}\text { PORCENTAJE } \\
\text { CRECIMIENTO }\end{array}$ \\
\hline 1991 & 762.041 & 92.495 & $(\%)$ & 6.0 \\
\hline 1992 & 772.778 & 99.949 & 12.1 & 76.0 \\
\hline 1993 & 1.217 .198 & 276.200 & 22.7 & \\
\hline
\end{tabular}

FUENTE: Secretaria de Educación Municipal 
Cuadro No. 7

\begin{tabular}{|c|c|c|c|c|c|}
\hline AÑO & $\begin{array}{c}\text { POBLACION } \\
\text { ATENDIDA }\end{array}$ & $\begin{array}{c}\text { RELACION } \\
\text { DOC - ALUM }\end{array}$ & $\begin{array}{c}\text { DESERCION } \\
\text { PORCENTAJE }\end{array}$ & $\begin{array}{c}\text { REPITENCIA } \\
\text { PORCENTAJE }\end{array}$ & $\begin{array}{c}\text { DEMANDA } \\
\text { OFERTA }\end{array}$ \\
\hline $\mathbf{1 9 9 0}$ & 450 & 31.3 & 8.4 & 2.6 & 0.7 \\
\hline $\mathbf{1 9 9 1}$ & 450 & 31.8 & 8.5 & 2.3 & 0.7 \\
\hline $\mathbf{1 9 9 2}$ & 450 & 30.36 & 9.3 & 2.4 & 0.7 \\
\hline $\mathbf{1 9 9 3}$ & 450 & 29.54 & 13.5 & 1.8 & 0.7 \\
\hline
\end{tabular}

Fuente: Formulario C-600 DANE

\section{Cuadro No. 8}

\begin{tabular}{|c|c|c|c|c|c|c|c|c|c|c|c|c|c|c|c|c|}
\hline \multirow[t]{3}{*}{ Año } & \multirow{2}{*}{\multicolumn{3}{|c|}{ NIVEL }} & \multirow{2}{*}{\multicolumn{2}{|c|}{ JORNAD }} & \multicolumn{6}{|c|}{ FINANCIACION } & \multirow{2}{*}{\multicolumn{5}{|c|}{ ALUMNOS }} \\
\hline & & & & & & & & MAEST & & & DOC & & & & & \\
\hline & BP & BS & MV & MAÑ & TAR & FER & DEP & MUN & OTRO & TOTAL & No & TOTAL & DES & REPIT & OFERTA & DEMANDA \\
\hline 89 & $\mathrm{X}$ & & & $\mathrm{X}$ & & 37 & & & & 37 & 2 & & & & & \\
\hline 90 & & & & & & & & & & & & & & & & \\
\hline 91 & & & & $\mathrm{X}$ & & 38 & & & & 38 & 2 & 604 & 21 & 57 & - & - \\
\hline 92 & & & & & & 38 & & & & 38 & 2 & 669 & 18 & 109 & - & - \\
\hline 93 & $\mathrm{X}$ & & & $\mathrm{X}$ & & 41 & & & & 41 & 2 & 667 & 21 & 130 & - & - \\
\hline
\end{tabular}

Fuente: Formulario C-600 DANE. Los datos que no aparecen es porque no están consignados en los formularios.

Cuadro No. 9

\begin{tabular}{|c|c|c|c|c|c|c|}
\hline AÑO & JORNADA & MATRICULA & $\begin{array}{c}\text { RELACION } \\
\text { DOC - ALUM }\end{array}$ & $\begin{array}{c}\text { DESERCION } \\
\text { PORCENTAJE }\end{array}$ & $\begin{array}{c}\text { REPITENCIA } \\
\text { PORCENTAJE }\end{array}$ & $\begin{array}{c}\text { DEMANDA } \\
\text { OFERTA }\end{array}$ \\
\hline $\mathbf{1 9 8 9}$ & & & & & & \\
\hline $\mathbf{1 9 9 0}$ & & & & & & \\
\hline $\mathbf{1 9 9 1}$ & MAÑANA & 604 & 16 & 3.4 & 9.4 & - \\
\hline $\mathbf{1 9 9 2}$ & MAÑANA & 669 & 17 & 2.6 & 16.2 & - \\
\hline $\mathbf{1 9 9 3}$ & MAÑANA & 667 & 16 & 3.1 & 19.4 & - \\
\hline
\end{tabular}

Fuente: Formulario C-600 DANE

El presupuesto municipal, asignado a educación, se incrementó de 1991 a 1992 en el $6 \%$ y de 1992 a 1993 en el 76\%; es evidente la importancia que el gobierno local le ha venido dando a este tema.

Según información de la Secretaría de Educación Departamental, la población atendida en secundaria para 1994 entre el sector oficial y el privado fue de 5.372 alumnos. En primaria, entre los dos sectores y en preescolar fue de 1.206.

Baranoa disponía en 1994 de 23 establecimientos, entre oficiales y privados de preescolar; 26 de básica primaria y siete de básica secundaria y media vocacional y un cuerpo de 40 docentes en preescolar, 216 en básica primaria y 245 en básica secundaria y media vocacional.

La mayoría de los docentes vinculados son pagados por el FER. Existen algunos pagados por el municipio, pero no se tiene un dato preciso sobre esta situación. El siguiente cuadro muestra la percepción de la descentralización en el sector municipal.

De esta información se puede percibir la existencia de problemas de orden fiscal y administrativo. Se nota una mayor dinámica y menos problemas en las instituciones seleccionadas: el Instituto Pedagógico Santa Ana y la Institución Mixta No. 1.

El "Instituto Pedagógico Santa Ana", es un establecimiento oficial que cuenta con los niveles de básica secundaria y media vocacional en la jornada de la mañana. En la planta de personal se registra un aumento del número de maestros de 33 a 38, y sólo en 1989 
contratan tres catedráticos. La participación de maestros pagados por el FER disminuye de 33 en 1992 a 30 en 1993, mientras que la participación de maestros pagados por el municipio aumenta de cinco en 1991 a ocho en 1993. En este caso se puede apreciar claramente un aumento de la participación del municipio en el pago de maestros, mientras que la participación del nivel nacional disminuye.

De 1989 a 1994 la población estudiantil atendida aumenta. La relación maestroalumno $17.8 \%$ en 1993 es muy baja en relación con el promedio nacional. La deserción es baja y la repitencia, aunque disminuyó levemente en 1992, se incrementó en 1994, y es alta para las características del plantel (ver cuadro No. 9).

La institución se ha considerado exitosa y se ha visto beneficiada por el proceso de descentralización tanto en lo referente a planta docente como en inversión en infraestructura física, razón por la cual la comunidad educativa valora en forma positiva este proceso.

La Escuela Mixta No. 1, es una institución educativa oficial que tiene los niveles de básica primaria en las jornadas de la mañana y de la tarde. La planta docente ha permanecido constante y cuenta con 12 maestros pagados por el FER y cinco pagados por el municipio. La población atendida tiende a disminuir en la jornada de la mañana y aumenta un poco en la jornada de la tarde. Ha sido una institución relativamente estable en docentes y alumnos. Los índices de repitencia son altos y han ido aumentando progresivamente en el tiempo.

La participación en la toma de decisiones frente a los cambios e innovaciones es un hecho generalizado en las instituciones estudiadas. En todas las instituciones, igualmente, se desarrollan actividades de integración con los miembros de la comunidad educativa, entre los cuales se destacan las siguientes: escuela de padres, actividades extracurriculares como bazares, concursos, encuentros deportivos, salidas ecológicas y participación de los padres en la construcción de obras para la institución. En algunos casos, los padres reducen su participación a la colaboración en obras de infraestructura, pero participan en la toma de decisiones. 


\section{Descentralización}

\section{ADMINISTRATIVA}

-El municipio enfrenta problemas para invertir en los establecimientos porque funcionan en Instalaciones que no pertenecen al Estado. Tiene problemas económicos por falta de recursos.

-Hay problemas administrativos por falta de precisión en las funciones del alcalde, secretario municipal y director de núcleo.

- El presupuesto vigente fue estructurado por la administración anterior y la actual no puede desarrollar su plan.

- Es necesario sensibilizar a los concejales para crear una cultura de pago de impuestos.

- El municipio atiende, además de la planta de personal docente, el personal administrativo y de servicios generales de los establecimientos.

- Existen diferentes formas de vinculación del personal y heterogeneidad de la normatividad al respecto, lo que dificulta su administración.
FISCAL

PEDAGÓGICA

- Se tienen proyectos de - La ley 115 obliga a invertir cofinanciación con ICETEX y recursos para mejorar la cacon PACES para becas.

- Un establecimiento ha tramitado en FINDETER un préstamo para ampliación y dotación de planta física.

- El presupuesto municipal no es suficiente para resolver los problemas de infraestructura, remodelación y dotación de los establecimientos.

Los alumnos perciben una participación más activa en la vida escolar, generando mejores aprendizajes y habilidades sociales, capacidad de concertación y asimilación del valor democrático de la convivencia.

Generalmente las instituciones mantienen relaciones con otras organizaciones, asociaciones y organismos presentes en el municipio del orden gubernamental y privado. Algunos con el sector apoyan programas de asesoría para el desarrollo de diversas actividades extracurriculares.

\section{Cuadro No. 11}

\begin{tabular}{|c|c|c|c|c|c|c|c|c|c|c|c|c|c|c|c|c|c|}
\hline \multirow[t]{3}{*}{ Año } & \multirow{2}{*}{\multicolumn{3}{|c|}{ NIVEL }} & \multirow{2}{*}{\multicolumn{2}{|c|}{ JORNAD }} & \multicolumn{7}{|c|}{ FINANCIACION } & \multirow{2}{*}{\multicolumn{5}{|c|}{ ALUMNOS }} \\
\hline & & & & & & \multicolumn{5}{|c|}{ MAESTROS } & \multicolumn{2}{|c|}{ DOCEN } & & & & & \\
\hline & BP & BS & MV & MAÑ & TAR & FER & DEP & MUN & OTRO & TOTAL & No & & TOTAL & DES & REPIT & OFERTA & DEMANDA \\
\hline 89 & & $\mathrm{X}$ & $\mathrm{X}$ & $\mathrm{COM}$ & & 29 & 3 & & 1 & 33 & 3 & FER & 485 & 3 & 74 & 445 & 664 \\
\hline & & & & & & & & & & & & & & & & & \\
\hline 90 & & & & & & & & & & & & & & & & & \\
\hline 91 & & & & & & 32 & & 5 & & 37 & 3 & FER & 475 & 5 & 61 & 475 & 546 \\
\hline 92 & & & & $\mathrm{COM}$ & & 33 & & 4 & & 37 & 3 & FER & 483 & 6 & 42 & 483 & 531 \\
\hline & & & $x$ & $\mathrm{COM}$ & & & & & & & & & & 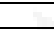 & & & \\
\hline & & & & & & & & & & & & & & & & & \\
\hline 93 & & & & $\mathrm{COM}$ & & 30 & & 8 & & 38 & 3 & FER & 678 & 4 & 69 & 678 & 685 \\
\hline
\end{tabular}

Fuente: Formulario C-600 DANE.

Tanto docentes como padres y alumnos tienen conocimiento sobre la politica de descentralización y una percepción positiva de ésta, ya que les ha permitido desarrollar su propio proyecto educativo institucional, solucionar autónomamente los problemas institucionales y de la comunidad educativa y desarrollar la creatividad e iniciativa al servicio de la educación en la localidad. 
Cuadro No. 12

\begin{tabular}{|c|c|c|c|c|c|}
\hline AÑO & $\begin{array}{c}\text { POBLACION } \\
\text { ATENDIDA }\end{array}$ & $\begin{array}{c}\text { RELACION } \\
\text { DOC - ALUM }\end{array}$ & $\begin{array}{c}\text { DESERCION } \\
\text { PORCENTAJE }\end{array}$ & $\begin{array}{c}\text { REPITENCIA } \\
\text { PORCENTAJE }\end{array}$ & $\begin{array}{c}\text { DEMANDA } \\
\text { OFERTA }\end{array}$ \\
\hline $\mathbf{1 9 8 9}$ & 445 & 14.7 & 0.61 & 15.2 & 1.5 \\
\hline $\mathbf{1 9 9 1}$ & 475 & 12.8 & 1 & 12.8 & 1.1 \\
\hline $\mathbf{1 9 9 2}$ & 483 & 13 & 1.2 & 8.7 & 1.1 \\
\hline $\mathbf{1 9 9 3}$ & 676 & 17.8 & 0.6 & 10.2 & 1 \\
\hline
\end{tabular}

Vale la pena señalar o advertir que la información estadística obtenida genera dudas y que el dato de docentes por institución no es claro, pues la relación docente-alumno es muy baja, especialmente en los planteles que ofrecen la básica secundaria.

\section{Conclusiones y recomendaciones}

El análisis de la información en los quince municipios estudiados permite plantear las siguientes conclusiones y recomendaciones:

Cuadro No. 13

\begin{tabular}{|c|c|c|c|c|c|c|c|c|c|c|c|c|c|c|c|c|c|}
\hline \multirow[t]{3}{*}{ Año } & \multirow{2}{*}{\multicolumn{3}{|c|}{ NIVEL }} & \multirow{2}{*}{\multicolumn{2}{|c|}{ JORNAD }} & \multicolumn{7}{|c|}{ FINANCIACION } & \multirow{2}{*}{\multicolumn{5}{|c|}{ ALUMNOS }} \\
\hline & & & & & & \multicolumn{5}{|c|}{ MAESTROS } & \multicolumn{2}{|c|}{ DOCEN } & & & & & \\
\hline & BP & BS & MV & MAÑ & TAR & FER & DEP & MUN & OTRO & TOTAL & No & & TOTAL & DES & REPIT & OFERTA & DEMANDA \\
\hline 90 & $x$ & & & $\mathrm{x}$ & & 12 & & 5 & & 9 & 1 & FER & 274 & 7 & 5 & 270 & 296 \\
\hline & & & & & $\mathrm{X}$ & & & & & 8 & & & 241 & 1 & 13 & 230 & 256 \\
\hline 91 & & & & $\mathrm{X}$ & & 12 & & 5 & & 9 & 1 & FER & 260 & 5 & 11 & 240 & 283 \\
\hline & & & & & $\mathrm{X}$ & & & & & 8 & & & 241 & 1 & 13 & 230 & 256 \\
\hline 92 & & & & $\mathrm{X}$ & & 12 & & 5 & & 9 & 1 & FER & 253 & 11 & 20 & 240 & 273 \\
\hline & & & & & $\mathrm{X}$ & & & & & 9 & & & 251 & & 17 & 240 & 259 \\
\hline 93 & & & & $\mathrm{X}$ & & 12 & & 5 & & 9 & 1 & FER & 248 & 3 & 31 & 240 & 266 \\
\hline & & & & & $\bar{x}$ & & & & & 8 & & & 252 & 4 & 28 & 240 & 262 \\
\hline
\end{tabular}

FUENTE: Formulario C-600 DANE

Cuadro No. 14

\begin{tabular}{|c|c|c|c|c|c|c|}
\hline AÑO & JORNADA & $\begin{array}{c}\text { POBLACION } \\
\text { ATENDIDA }\end{array}$ & $\begin{array}{c}\text { RELACION } \\
\text { DOC - ALUM }\end{array}$ & $\begin{array}{c}\text { DESERCION } \\
\text { PORCENTAJE }\end{array}$ & $\begin{array}{c}\text { REPITENCIA } \\
\text { PORCENTAJE }\end{array}$ & $\begin{array}{c}\text { DEMANDA } \\
\text { OFERTA }\end{array}$ \\
\hline $\mathbf{1 9 9 0}$ & Mañana & 274 & 30.4 & 2.5 & 1.8 & 1.1 \\
\hline & Tarde & 241 & 30.1 & 0.41 & 5.3 & 1.1 \\
\hline $\mathbf{1 9 9 1}$ & Mañana & 260 & 28.9 & 1.9 & 4.2 & 1.1 \\
\hline & Tarde & 241 & 30.1 & 0.41 & 5.4 & 1.1 \\
\hline $\mathbf{1 9 9 2}$ & Mañana & 253 & 28.1 & 4.3 & 1.9 & 1.1 \\
\hline & Tarde & 251 & 27.9 & 0 & 6.7 & 1.1 \\
\hline $\mathbf{1 9 9 3}$ & Mañana & 248 & 27.5 & 1.2 & 12.5 & 1.1 \\
\hline & Tarde & 252 & 31.5 & 1.5 & 10.31 & 1.1 \\
\hline
\end{tabular}

FUENTE: Formulario C-600 DANE

- $\quad$ El proceso de descentralización en general y de la educación en particular, cuenta con gran legitimidad y aceptación tanto entre funcionarios como entre la comunidad educativa.

- Se percibe en los actores consultados un buen conocimiento de las normas descentralizadoras, una actitud abierta y positiva al cambio, a excepción de algunos funcionarios municipales en uno de los departamentos estudiados, y buena voluntad por parte de las autoridades municipales e institucionales para asumir la autonomía en el manejo de la educación. 
- Entre las ventajas reconocidas a la descentralización, la más relevante es la posibilidad de manejar directamente los recursos, movilizar recursos adicionales, generar una mayor capacidad de gestión a nivel local y el hecho de que se está contribuyendo a la construcción de una cultura de planeación con participación tanto en las entidades territoriales como en los establecimientos educativos, dado que la descentralización, además de constituir un proceso de transferencia de competencias y de recursos del nivel central a las instancias locales, es un proceso de cambio cultural por cuanto implica modificaciones en la forma de percibir lo local, en el modo de hacer las cosas y de pensar en la solución de los problemas.

- La mayor dificultad radica en la insuficiencia de recursos en relación con la magnitud de los problemas por resolver y de las responsabilidades asignadas.

- Son muy deficientes los sistemas de información, e inexistentes los de evaluación de proceso y de impacto.

- Existe colisión de competencias entre la supervisión y los núcleos. La función de aquella hay que replantearla a la luz de las normas de descentralización y del papel del núcleo en el municipio.

- La nuclearización está jugando un papel importante en la administración de la educación en los municipios. Tiene amplia acogida, tanto por los funcionarios como por los establecimientos. Para hacer más eficiente la gestión del núcleo se necesita revisar sus funciones y los niveles de coordinación y articulación con la alcaldía, la secretaría municipal de educación, la supervisión educativa y el departamento y dotarlo de capacidad operativa para poder funcionar.

- Con la descentralización la capacitación ha ganado importancia como punto de preocupación de las autoridades locales. Se está comenzando a elaborar propuestas dentro de los planes de desarrollo educativo y se está buscando la vinculación de las universidades para esta actividad.

- Se percibe una debilidad en la gestión administrativa de las localidades y de los establecimientos. Se requiere incrementar la función de asesoría y asistencia técnica de la nación y de los departamentos para subsanar esta situación. La función de asesoría y asistencia técnica a los municipios por parte del departamento está desdibujada.

- La escasez de recursos y las posibilidades que plantea la descentralización han contribuido a estimular la iniciativa y la creatividad a nivel local para movilizar recursos adicionales mediante la cofinanciación y elaboración y presentación de proyectos. Esta iniciativa se podría potenciar con una adecuada capacitación y asesoría técnica a las autoridades locales.

- Un campo que está por explorarse y que ofrece grandes posibilidades es el de las alianzas estratégicas entre el sector público y el privado para adelantar programas conjuntos de beneficio colectivo.

- Como todo proceso de cambio, la descentralización tiene sus propios tiempos, dinámica y complejidad, que es necesario tratar de comprender a través de investigaciones como la presente. La descentralización es un proceso que se construye colectivamente paso a paso. El papel de las normas es el de abrir camino e inducir el proceso. Una vez abierto, entran en juego las iniciativas y potencialidades 
locales que enriquecen la marcha del proceso y le dan su rasgo característico. No hay que temer a las dificultades que se operan sobre la marcha. Las dificultades son inherentes a todo proceso de cambio, y lejos de perjudicar enriquecen. Los problemas vistos como una oportunidad constituyen un estímulo al desarrollo de la iniciativa, a la creatividad y a las potencialidades locales.

- Un factor que influye en las posibilidades de éxito del proceso de descentralización y que atenúa las dificultades, es la actitud con que se asuma el cambio por parte de los diferentes actores involucrados (funcionarios y comunidades). 